\title{
The YPLGVG sequence of the Nipah virus matrix protein is required for budding
}

\author{
Jared R Patch ${ }^{1,4}$, Ziying Han²,5, Sarah E McCarthy' ${ }^{2,6}$, Lianying Yan ${ }^{1}$, Lin- \\ Fa Wang 3 , Ronald N Harty ${ }^{2}$ and Christopher C Broder*1
}

\begin{abstract}
Address: ${ }^{1}$ Department of Microbiology and Immunology, Uniformed Services University, Bethesda, Maryland 20814, USA, ${ }^{2}$ Department of Pathobiology, School of Veterinary Medicine, University of Pennsylvania, 3800 Spruce St, Philadelphia, PA 19104-6049, USA, 3CSIRO Livestock Industries, Australian Animal Health Laboratory, Geelong, Victoria 3220, Australia, ${ }^{4}$ Plum Island Animal Disease Center, Agricultural Research Service, USDA, Greenport, NY 11944, USA, ${ }^{5}$ Fox Chase Cancer Center, 333 Cottman Avenue, Philadelphia, PA 19111-2497, USA and ${ }^{6}$ United States Army Research Institute of Infectious Diseases, Virology Division, 1425 Porter Street, Fort Detrick, MD 21702, USA

Email: Jared R Patch - Jared.Patch@ARS.USDA.GOV; Ziying Han - Ziying.Han@fccc.edu; Sarah E McCarthy - Sarah.E.Mccarthy@us.army.mil; Lianying Yan - lyan@usuhs.mil; Lin-Fa Wang - Linfa.Wang@csiro.au; Ronald N Harty - rharty@vet.upenn.edu;

Christopher C Broder* - cbroder@usuhs.mil

* Corresponding author
\end{abstract}

Published: 10 November 2008

Virology Journal 2008, 5:137 doi:10.1186/1743-422X-5-137

This article is available from: http://www.virologyj.com/content/5/I/I37

(C) 2008 Patch et al; licensee BioMed Central Ltd.

This is an Open Access article distributed under the terms of the Creative Commons Attribution License (http://creativecommons.org/licenses/by/2.0), which permits unrestricted use, distribution, and reproduction in any medium, provided the original work is properly cited.
Received: 23 October 2008

Accepted: 10 November 2008

\begin{abstract}
Background: Nipah virus (NiV) is a recently emerged paramyxovirus capable of causing fatal disease in a broad range of mammalian hosts, including humans. Together with Hendra virus $(\mathrm{HeV})$, they comprise the genus Henipavirus in the family Paramyxoviridae. Recombinant expression systems have played a crucial role in studying the cell biology of these Biosafety Level-4 restricted viruses. Henipavirus assembly and budding occurs at the plasma membrane, although the details of this process remain poorly understood. Multivesicular body (MVB) proteins have been found to play a role in the budding of several enveloped viruses, including some paramyxoviruses, and the recruitment of MVB proteins by viral proteins possessing late budding domains (Ldomains) has become an important concept in the viral budding process. Previously we developed a system for producing NiV virus-like particles (VLPs) and demonstrated that the matrix (M) protein possessed an intrinsic budding ability and played a major role in assembly. Here, we have used this system to further explore the budding process by analyzing elements within the $M$ protein that are critical for particle release.

Results: Using rationally targeted site-directed mutagenesis we show that a NiV M sequence YPLGVG is required for $M$ budding and that mutation or deletion of the sequence abrogates budding ability. Replacement of the native and overlapping Ebola VP40 L-domains with the NiV sequence failed to rescue VP40 budding; however, it did induce the cellular morphology of extensive filamentous projection consistent with wild-type VP40-expressing cells. Cells expressing wild-type NiV M also displayed this morphology, which was dependent on the YPLGVG sequence, and deletion of the sequence also resulted in nuclear localization of $M$. Dominant-negative VPS4 proteins had no effect on NiV M budding, suggesting that unlike other viruses such as Ebola, NiV M accomplishes budding independent of MVB cellular proteins.

Conclusion: These data indicate that the YPLGVG motif within the NiV M protein plays an important role in M budding; however, involvement of any specific components of the cellular MVB sorting pathway in henipavirus budding remains to be demonstrated. Further investigation of henipavirus assembly and budding may yet reveal a novel mechanism(s) of viral assembly and release that could be applicable to other enveloped viruses or have therapeutic implications.
\end{abstract}




\section{Background}

Nipah virus (NiV) and Hendra virus $(\mathrm{HeV})$ are emerging members of the family Paramyxoviridae that are distinguished by their ability to cause fatal disease in both animal and human hosts, and comprise the genus Henipavirus $[1,2]$. HeV was recognized as a novel paramyxovirus in 1994 during an outbreak in eastern Australia that resulted in the death of one human as a consequence of virus transmission from infected horses. Another person later died from relapsed encephalitis as a result of $\mathrm{HeV}$ infection that was identified retrospectively [3]. Repeated $\mathrm{HeV}$ spillover events have since occurred five times, all involving horses, with the most recent occurrence in July 2008 which also involved two human cases, one of which was fatal $[4,5]$. NiV was identified during an outbreak of severe encephalitis in Malaysia and Singapore that began in 1998 and continued into 1999. In contrast to the $\mathrm{HeV}$ outbreak, this NiV episode involved hundreds of people and more than 100 deaths, with pigs serving as the intermediate amplifying host $[6,7]$. Since 1998 there have been 9 recognized occurrences of $\mathrm{NiV}$ infection of people, primarily in Bangladesh and India with the most recent in March 2008 [8-14]. The mortality in humans has been higher $(\sim 75 \%)$ in these spillover events, along with evidence of human-to-human transmission and the apparent lack of an intermediate host [8,15-17].

Several species of fruit bats (flying foxes) of the Pteropus genus serve as the primary natural reservoirs of $\mathrm{HeV}$ and $\mathrm{NiV}$, although to date evidence of henipavirus infection in 5 other bat species across 5 genera has been reported (reviewed in [5]). NiV has been isolated from bat urine and partially eaten fruit, which suggests that it is relatively easy to obtain from the environment $[18,19]$. Indeed, direct transmission of NiV from flying foxes to humans from contaminated food sources has been suggested $[9,20]$. The Centers for Disease Control and Prevention (CDC) and the National Institute of Allergy and Infectious Diseases (NIAID) have classified $\mathrm{HeV}$ and $\mathrm{NiV}$ as priority pathogens, and work with live virus requires Biosafety Level-4 (BSL-4) containment.

Paramyxoviruses are enveloped viruses that replicate in the cytoplasm and contain a genome consisting of singlestranded negative-sense RNA [21]. The genome contains 6 principle genes: nucleocapsid $(\mathrm{N})$, phosphoprotein $(\mathrm{P})$, matrix $(\mathrm{M})$, the fusion $(\mathrm{F})$ and attachment $(\mathrm{HN}, \mathrm{H}$, or $\mathrm{G})$ proteins, and the polymerase $(\mathrm{L})$, along with accessory proteins that vary according to viral species [21]. The requirement for high containment conditions for working with live $\mathrm{HeV}$ or $\mathrm{NiV}$ has necessitated the development of recombinant protein expression systems as tools for elucidating details of the henipavirus life cycle. We previously established a virus-like particle (VLP) system in order to study the assembly and budding process of $\mathrm{NiV}$, and determined that the $\mathrm{M}$ protein plays a central role in $\mathrm{NiV}$ assembly [22]. We also observed that expression of $M$ alone resulted in the release of VLPs, as was also reported by Ciancanelli and Basler $[22,23]$. Other paramyxovirus $\mathrm{M}$ proteins with this property include Sendai virus $(\mathrm{SeV})$ $[24,25]$, human parainfluenza virus type 1 (hPIV-1) [26], and Newcastle disease virus (NDV) [27]. In contrast, simian virus 5 (SV5) (parainfluenza virus 5 (PIV5)) [28] requires expression of $\mathrm{M}$ along with $\mathrm{N}$ and either $\mathrm{F}$ or $\mathrm{HN}$ to produce VLPs [29]. The mechanism(s) that govern the budding of $\mathrm{M}$ remain unknown. A current area of interest in enveloped virus assembly and morphogenesis is the contribution of L-domains, which are protein motifs first identified in retroviral Gag precursor molecules that are important for late steps in assembly and budding (reviewed in [30-32]). L-domains interact with components of cellular machinery involved in multivesicular body (MVB) formation and are thought to commandeer those proteins for use in viral budding. The involvement of L-domains in virus assembly and budding has been extended to other enveloped virus families including arenaviruses [33], filoviruses [34,35], rhabdoviruses [35-37], and paramyxoviruses $[38,39]$. In certain cases, different Ldomains can be functionally interchanged or mediate their activity in a position-independent manner within the protein molecule; however, these properties are not universal and it is now apparent that the surrounding regions or context within which the L-domain motif lies can be important for its function [31,40-42]. There are several well-characterized examples where the mutation or removal of a viral L-domain motif within, for example, the $\mathrm{M}$ protein, will abrogate the protein's ability to bud from expressing cells $[35,38,43-45]$.

L-domain amino acid motifs that have been identified (along with the MVB protein each interacts with) include: P(T/S)AP (Tsg101), PPxY (Nedd4-like E3 ubiquitin ligases), $\mathrm{YP}(\mathrm{x})_{\mathrm{n}} \mathrm{L}$ (AIP1/Alix), and $\varnothing \mathrm{PxV}$ (none identified), where $\mathrm{x}$ is any amino acid and $\varnothing$ is any aromatic amino acid [30-32]. Until the identification of the novel FPIV sequence in SV5 M [38], paramyxoviruses were not known to utilize L-domains in their assembly and morphogenesis. However, the $\mathrm{M}$ protein of many paramyxoviruses, including $\mathrm{NiV}$ and $\mathrm{HeV}$, do not contain any identified L-domains, including the SV5 FPIV motif [38]. The MVB protein AIP1/Alix was shown to help facilitate $\mathrm{SeV}$ virion and VLP release through interactions with an undetermined sequence in the $\mathrm{C}$ protein, as well as through a recently identified YLDL sequence in the $\mathrm{M}$ protein $[39,46]$; however, a conflicting study failed to find a role for AIP1/Alix in SeV virion production [47]. Ciancanelli and Basler reported that $\mathrm{NiV} M$ contains a sequence, YMYL, that is required for VLP budding and, based on its ability to complement Ebola VP40 VLP for- 
mation, suggested that this sequence serves as an Ldomain [23].

In this study, we report the identification of an amino acid sequence motif (YPLGVG) that is required for $\mathrm{NiV}$ and $\mathrm{HeV} \mathrm{M}$ budding, and that appeared to partially complement the native Ebola VP40 phenotype but was VPS4independent. However, complementation of the Ebola VP40 mutant was observed only in its effects on cellular morphology, characterized by extensive filamentous projections, and not in Ebola VP40 budding. In addition, cells expressing wild-type $\mathrm{NiV} M$ were noted to have a cellular morphology similar to that of VP40 expressing cells, and deletion of the YPLGVG sequence resulted in abrogation of this morphology and nuclear localization of $\mathrm{M}$.

\section{Results \\ Mutation of the YPLGVG motif in NiV matrix abrogates budding}

Most L-domains described to date contain one or more proline residues. Because the NiV M protein does not contain any of the exact known L-domain motifs, we examined the entire $M$ protein sequence for proline residues with surrounding amino acids that we considered to be similar to known L-domains. Following this analysis, we identified 3 sequences of interest with the intent of mutating the proline residues within these putative motifs to alanine (Fig. 1A and 1B). Residue P35 was targeted because it aligned closely to the SV5 FPIV (ØPxV) motif, although there were no further sequence similarities. P93 is located in a sequence similar to the $\mathrm{YP}(\mathrm{x})_{\mathrm{n}} \mathrm{L}$ motif, and the P329 and P332 residues were targeted because of sequence similarity to the $\mathrm{P}(\mathrm{T} / \mathrm{S}) \mathrm{AP}$ motif. It was also noted that P93, P329 and P332 are all well conserved among paramyxovirus $M$ proteins but are absent in SV5 M (Fig. 1A), which further suggested that these proline residues might be part of an L-domain.

The mutant $\mathrm{M}$ gene cassettes were expressed in cells, pelleted through a 10\% sucrose cushion, and analyzed by immunoprecipitation and SDS-PAGE followed by autoradiography. The result of this comparison revealed that each of the mutant $M$ proteins retained budding ability except for the P93A mutant, which exhibited a marked reduction in $M$ protein release (Fig. 1C). The P93 residue is part of an amino acid sequence (YPLGVG) that resembles the $\mathrm{YP}(\mathrm{x})_{\mathrm{n}} \mathrm{L}$ motif and also contains residues that are well conserved among paramyxovirus $M$ proteins (Fig. 1A). To confirm this observation and further characterize the role of this sequence in $\mathrm{M}$ protein release, additional $\mathrm{M}$ mutants were constructed: Y92A, L94A, and $492-97$ (Fig. 2A), that were then tested in the budding assay. The result of this experiment revealed that none of the additional mutant $\mathrm{M}$ proteins, with the exception of the P93A mutant, which sometimes retained a low level of budding activity, were released from expressing cells (Fig. 2B). All of the mutants were expressed at levels similar to wildtype $\mathrm{NiV} \mathrm{M}$, and these findings confirm the importance of this motif. We previously observed that $\mathrm{HeV} \mathrm{M}$ is also released into the culture supernatant when expressed alone, although less efficiently than NiV M (unpublished observation). To determine whether the conserved YPLGVG sequence is required for $\mathrm{HeV} M$ release, we constructed HeV M P93A and $\Delta 92-97$ mutants and tested them in the budding assay. In contrast to wild-type $\mathrm{HeV}$ $M$, which was released into the supernatant, we did not detect release of the P93A mutant (Fig. 2C). We were unable to detect expression of $\mathrm{HeV} M \Delta 92-97$ (data not shown), possibly due to mis-folding and degradation. These data suggest that the YPLGVG sequence is required for $\mathrm{NiV}$ and $\mathrm{HeV} \mathrm{M}$ budding, and may also play a role in $\mathrm{HeV}$ M stability.

\section{The YPLGVG matrix motif can partially restore a defective VP40 phenotype}

A notable feature of most viral L-domain motifs is their inherent transferability to other $M$ proteins defective in budding $[31,38,44]$. Therefore, we sought to determine whether this newly identified $\mathrm{NiV} M$ sequence could impart budding activity within the context of a different viral background. The Ebola VP40 protein contains two overlapping L-domain motifs, the PTAPPEY sequence, and deletion of these L-domains renders the protein defective in release [35]. A VP40 mutant was constructed in which we replaced the native L-domains and flanking residues with the NiV M protein YPLGVG motif (Fig. 3A), and this mutant was tested for budding activity. The results of this experiment revealed that, although some budding was evident, the $\mathrm{NiV} M$ sequence failed to rescue VP40 budding above the basal level observed for the VP40 deletion mutant (data not shown). However, immunofluorescent confocal microscopy revealed that cells expressing VP40-NiV that contained the YPLGVG motif had a similar morphology to those expressing wild-type VP40, which was characterized by extensive filamentous projections that were frequently branching and fragmented (Fig. 3B). Martin-Serrano and co-workers, as well as others, previously observed this phenotype in cells expressing VP40 $[41,48,49]$. This cellular morphology was not observed when the native overlapping L-domains were deleted from VP40 (VP40 $\triangle \mathrm{PT} / \mathrm{PY}$ ) (Fig. 3B). However, cells expressing wild-type NiV M showed a filamentous phenotype similar to those expressing VP40 (Fig. 4). In contrast, the NiV M $\Delta 92-97$ mutant, that was totally defective in budding, had an absence of the filamentous structures and appeared to localize at the nucleus. Cells expressing NiV M P93A displayed a somewhat intermediate phenotype with less pronounced filamentous structures and this phenotype also corresponded to the partial buddingdefective phenotype (Fig. 4). Together, these results sup- 
A

NiV 1 MEPDIKS I S SESMEGVS - DFSPS SWE HGGYLDKVEPE I DENGSM I PKYK I YTPGANERKYNNYMYL I CYGFVEDVERTPETG HeV 1 MDFSVSDNLDGPIEGVS - DFSPTSWENGGYLDKVEPE I DKHGSMIPKYKIYTPGANERKFNNYMYMI CYGFVEDVERSPESG TPMV 1 MYPSAPR I DEAPVVDCEYEF I PTTWLEKGYLSAMKVESDHNGK I I PSVRVVNPGWGERKTSGYMYL I MHG IVEDVPKDGDTE $\mathrm{MeV} \quad 1 \ldots \ldots \ldots \ldots$ MTEIY - DFDKSAWD IKGS I AP IQPT TYSDGRLVPQVRV I DPGLGDRKDECFMYMFLLGVVEDSDPLGPP. $\mathrm{SeV} \quad 1 \ldots \ldots \ldots \ldots$. . . . . $\begin{array}{llll}\mathrm{SeV} & 1 \ldots \ldots \\ \mathrm{NDV} & 1 \ldots . .\end{array}$ SV5 $\quad 1 \ldots \ldots . . . . . .9 P S$ I I I PADPTNPRQS I KAFP IV INSDGGEKGRLVKQLRTTYLNDLDTHEPLVTF INTYGF I YEQDRGNT IV

NiV $\quad 82 \ldots \ldots . . . . . . K R K K$ IRT I AAYPLGVGKSASHPQDLLEELCSLKVTVRRTAGSTEK IVFGSSGPLNHLVPWKKVLTSGS IFNAVK

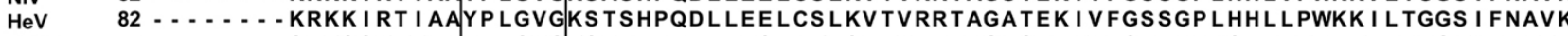
TPMV $\quad 83 \cdots \cdots .-$ QRYSGKTYAAFPLGVGKSNATPDDLLTSMNKLQITVRRTAGAGERIVFGNNAPLGALFPWRVLDFGAVFTAYK MeV $\quad 69 \ldots \ldots \ldots . . . . .$. IGRAFGS LPLGVGRSTAKPEELLKEATELDIVVRRTAGLNEKLVFYNNTPLTLLTPWRKVLTTGSVFNANQ SeV 70 SVSDLTEHTGYS I CGSGSLPIGVAKYHGSDQELLKACTDLR I TVRRTVRAGEM IVYMVDS I GAPLLPWSGRLRQGM I FNANK $\begin{array}{ll}\mathrm{SeV} & 70 \mathrm{SV} \\ \mathrm{NDV} & 76 \mathrm{G}-\mathrm{II} \text { IDDKPKRELLSAAMLCLGSVPNTGDLIELARACLTMMVTCKKSATNTERMVFSVVQAPQVLQSCRVVANKYSSVNAVK }\end{array}$ SV5 73 G - - EDQLGKKREAVTAAMVTLGCGPNLPSLGNVLGQLRE FQVTVRKTSSKAEEMVFE IVKYPRI FRGHTL IQKGLVCVSAEK

NiV 156 VCRNVDQIQLDKHQALR I FFLS I TKLNDSG I YM I PRTMLEFRRNNA I AFNLLVYLK I DADLSKMG I QGSLDKDGFK - - VASF $\mathrm{HeV} 156$ VCRNVDQ IQLEKQQSLR IFFLS I TKLNDSG I YM I PRTMLEFRRNNA I AFNLLVYLK I DADLAKAG IQGS FDKDGTK - - VASF TPMV 157 VCLSVES ISLFTPQRFRPLFLTVTLLTDNGLYKAPSLFADFRASKAVSFNLLARLTVNNKSGKDYLATAPASDTKQ - - VVSF $\mathrm{MeV} \quad 140$ VCNAVNLIPLDTPQRFRVVYMS I TRLSDNGYYTVPRRMLEFRSVNAVAFNLLVTLRI DKA IGPGK I IDN - - AEQLP - - EATF SeV 152 VALAPQCLPVDKD I RFRVVFVNGTSLGA I I I AK I PKTLADLALPNS I SVNLLVTLKTG I STEQKGVLPVLDDQGEK - - KLNF NDV 156 HVKAPEK IPGSGTLEYKVNFVSLTVVPKKDVYK I PAAVLK I SGSSLYNLALNVT INVEVDPRSPLVKSLSKSDSGY - - YANL SV5 153 FVKSPGK I QSGMDYLFIPTFLSVTYCPAA I KFQVPGPMLKMRSRYTQS LQLELMIRI LCKPDSPLMKVHTPDKEGRGCLVSV

NiV 236 MLHLGNFV - - RRAGKYYSVDYCRRK I DRMKLQFSLGS I GGLSLH IKINGV I SKRLFAQMGFQKNLCFSLMD INPWLNRLTWN $\mathrm{HeV} 236$ MLHLGNFV - - RRAGKYYSVEYCKRK I DRMKLQFS LGS I GGLSLH I K I NGV I SKRLFAQMGFQKNLCFS LMD I NPWLNRL TWN TPMV 237 MVHIGNFV - - RKGGDVYSNSYCKKK I DRMDLQFALGAVGGLSFH IK I NGKMSKT LMTQLGFHRNLCYS I MD INPDLNKK IWN MeV 218 MVHIGNFR - RKKSEVYSADYCKMK I EKMGLVFALGG I GGTSLH IRS TGKMSKT LHAQLGFKKTLCYP LMDI NEDLNRLLWR SeV 232 MVHLGLIR - - RKVGK IYSVEYCKSK IERMRL I FSLGL IGG I SFHVQVTGTLSKTFMGQLAWKRAVCFPLMDVNPHMNLV IWA NDV 236 FLH IGLMTTVDRKGKKVTFDKLEKK IRSLDLSVGLSDVLGPSVLVKARGARTKLLAPFFSSSGTACYP I ANASPQVAK I LWS SV5 235 WLHVCN I FKSGNKNGSEWQEYWMRKCANMQLEVS I ADMWGPT I I I HARGH I PKS AKLF FGKGGS CHP LHEVVPSVTKT LWS

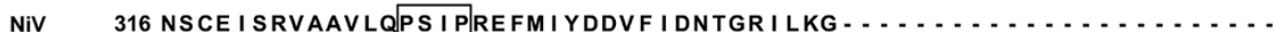

$\mathrm{HeV} \quad 316$ NSCEISRVAAVLQPSVPREFMIYDDVFIDNTGKILKG $\ldots \ldots \ldots \ldots \ldots \ldots \ldots \ldots$

TPMV $\quad 317$ SSCRITSVAAILQPSVSKDFKIYHDVFIDNTGK IMG $\ldots \ldots \ldots \ldots \ldots \ldots \ldots \ldots$

$\mathrm{MeV} \quad 298$ SRCKIVRIQAVLQPSVPQEFR IY DDV I INDDQGLFKVL $\ldots \ldots \ldots$

SeV 312 ASVEITDV

NDV 318 QTACLRSVK I I I QAGTQRAVAVTADHEVTSTKLEKGHTLAKYNPFKK
SV5 317 VGCEITKAKA I IQESS ISLLVETTDIISPKVKISSKHRRFVSNWGLKKTKSLPNLTELE

B

\begin{tabular}{l|l} 
L-domains & NiV M Sequences \\
\hline$\varnothing P x V$ & 29 YLDKVEPEEID \\
YP(x) $)_{n}$ L & 92 Y $\underline{P} L G V G$ \\
P(T/S)AP & $329 \underline{\text { PSI }}$
\end{tabular}

C

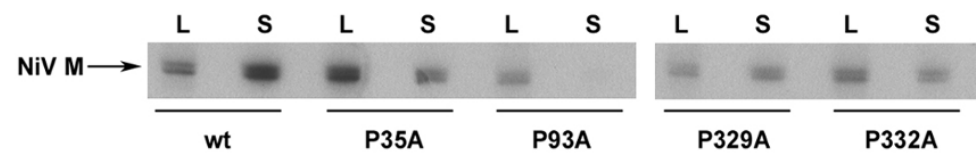

Figure I

Site-directed proline mutagenesis. (A) ClustalW alignment of the M proteins from Nipah virus (NiV), Hendra virus (HeV), Tupaia paramyxovirus (TPMV), measles virus (MeV), Sendai virus (SeV), Newcastle disease virus (NDV), and simian virus 5 (SV5). Sequences of interest are boxed. Alignment was performed as described in the Methods. (B) Known L-domains are shown along with corresponding hypothetical L-domain sequences of $\mathrm{NiV} M$ (boxed in $\mathrm{A}$ ). Underlined proline residues were mutated to alanine. (C) Mutant NiV M proteins, along with wild-type, were expressed in cells and released protein was pelleted through $10 \%$ sucrose. Proteins derived from the cell lysate $(\mathrm{L})$ or culture supernatant $(\mathrm{S})$ were immunoprecipitated using $\mathrm{MAb}$ F45G5 and analyzed by SDS-PAGE followed by autoradiography as described in the Methods.

port the hypothesis that the NiV M-YPLGVG amino acid motif plays an important role in NiV M budding, and that it acts through a mechanism that is, in part, transferable to other viruses.

\section{NiV matrix budding is not dependent on VPS4A/B}

The involvement of certain components of the cellular MVB machinery has been demonstrated in several other viral systems (reviewed in [30-32]). A powerful technique that has helped facilitate the demonstration of these relationships has been the use of dominant-negative mutant versions of one or more of the protein components of the MVB complexes [31]. Dominant-negative (DN) mutants of the paralogous MVB proteins VPS4A and VPS4B have been shown to impair release of most viruses that use Ldomains to accomplish budding [32]. To determine whether VPS4A has a functional role in NiV M VLP egress, we evaluated $\mathrm{NiV} M$ release in the presence of VPS4A- 


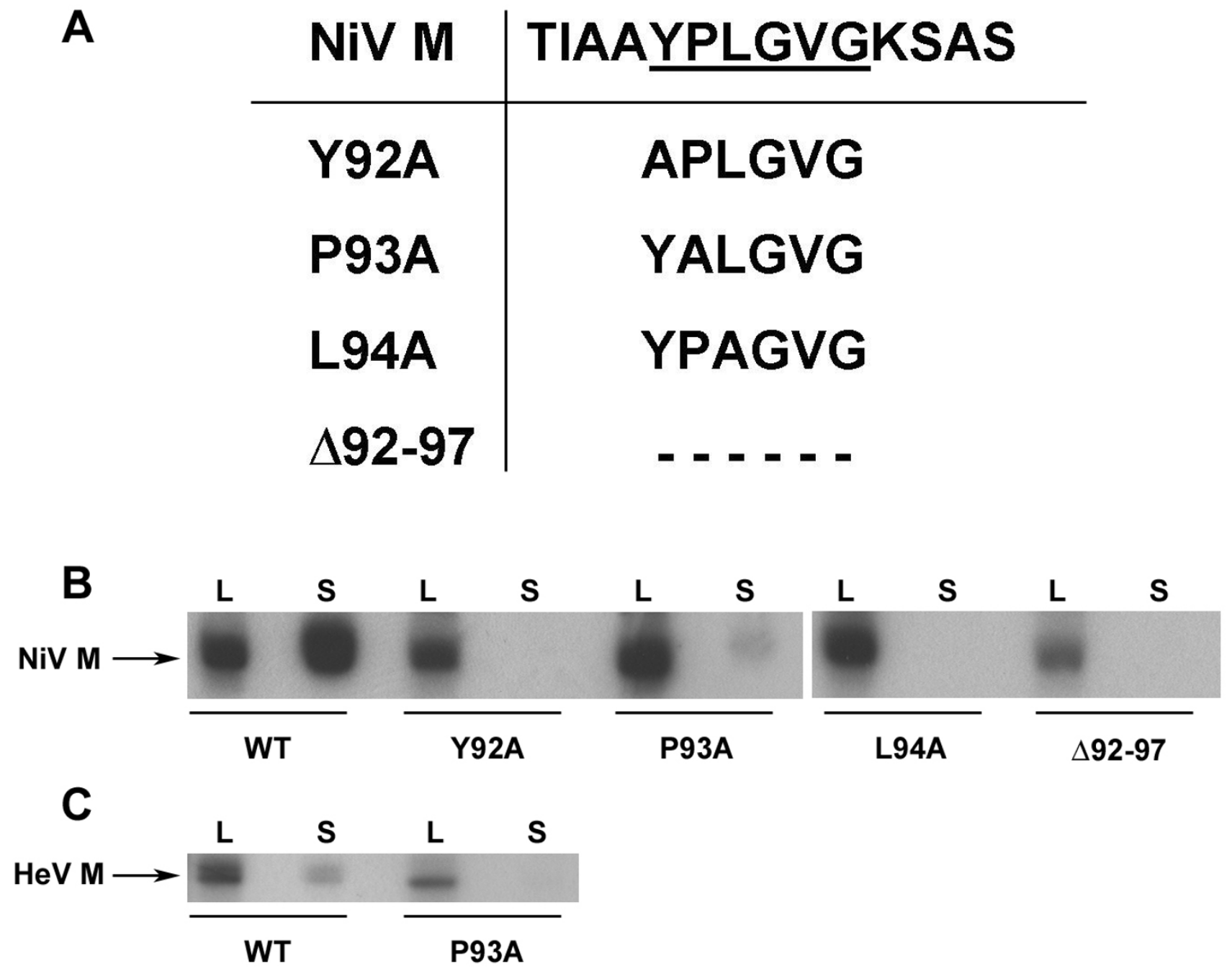

Figure 2

NiV M sequence required for budding and possible late domain element. (A) NiV M mutants were constructed with single alanine substitution mutations in the YPLGVG sequence (underlined), or with the whole sequence deleted (dashes). (B) Wild-type NiV M and the mutants depicted in A were all expressed in cells and released protein was pelleted through a $20 \%$ sucrose cushion. Proteins derived from the cell lysate $(L)$ or culture supernatant $(S)$ were immunoprecipitated with MAb F45G5 and analyzed by SDS-PAGE followed by autoradiography. (C) Wild-type and mutant P93A HeV M were expressed in cells and a budding assay was performed as described in the Methods.

E228Q, a DN VPS4A mutant. SV5 VLP release, which is significantly reduced in the presence of DN VPS4A [38], was evaluated in parallel as a control. Cells were transfected with expression plasmids for SV5 proteins (M, N, F, and $\mathrm{HN}$ ) or NiV M, along with $100 \mathrm{ng}$ (per well) of plasmid containing Green Fluorescent Protein (GFP) fused to either wild-type or DN VPS4A. The quantities of the SV5 plasmids used were as described by Schmitt and co-workers [29] (N: $50 \mathrm{ng}$; M: $0.4 \mu \mathrm{g} ; \mathrm{F}: 0.75 \mu \mathrm{g}$; HN: $0.75 \mu \mathrm{g}$ ), and $0.4 \mu \mathrm{g}$ (per well) of NiV M was used along with empty vector for equivalent total DNA. Culture supernatants were clarified, and VLPs were centrifuged through a $10 \%$ sucrose cushion. Immunoprecipitation and SDS-PAGE analysis of the pellet revealed that SV5 VLPs (as indicated by $M$ detection) were released in the presence of wild-type VPS4A, but not in the presence of DN VPS4A, as expected (Fig. 5A). In contrast, DN VPS4A had no effect on NiV M release (Fig. 5A). The difference observed between SV5 and NiV M release was not due to unequal VPS4A expression, which was equivalent in each group (Fig. 5B). NiV M release was similarly unaffected in the presence of DN VPS4B or both DN VPS4A and DN VPS4B (data not shown). These results suggest that NiV M VLP formation is not dependent on functional VPS4 proteins. 
A

\section{VP40 WT MRR VILPTAPPEYMEAIYPVRS N VP40-NiV MRTIAAYPLG VGKSAYPVRS N}

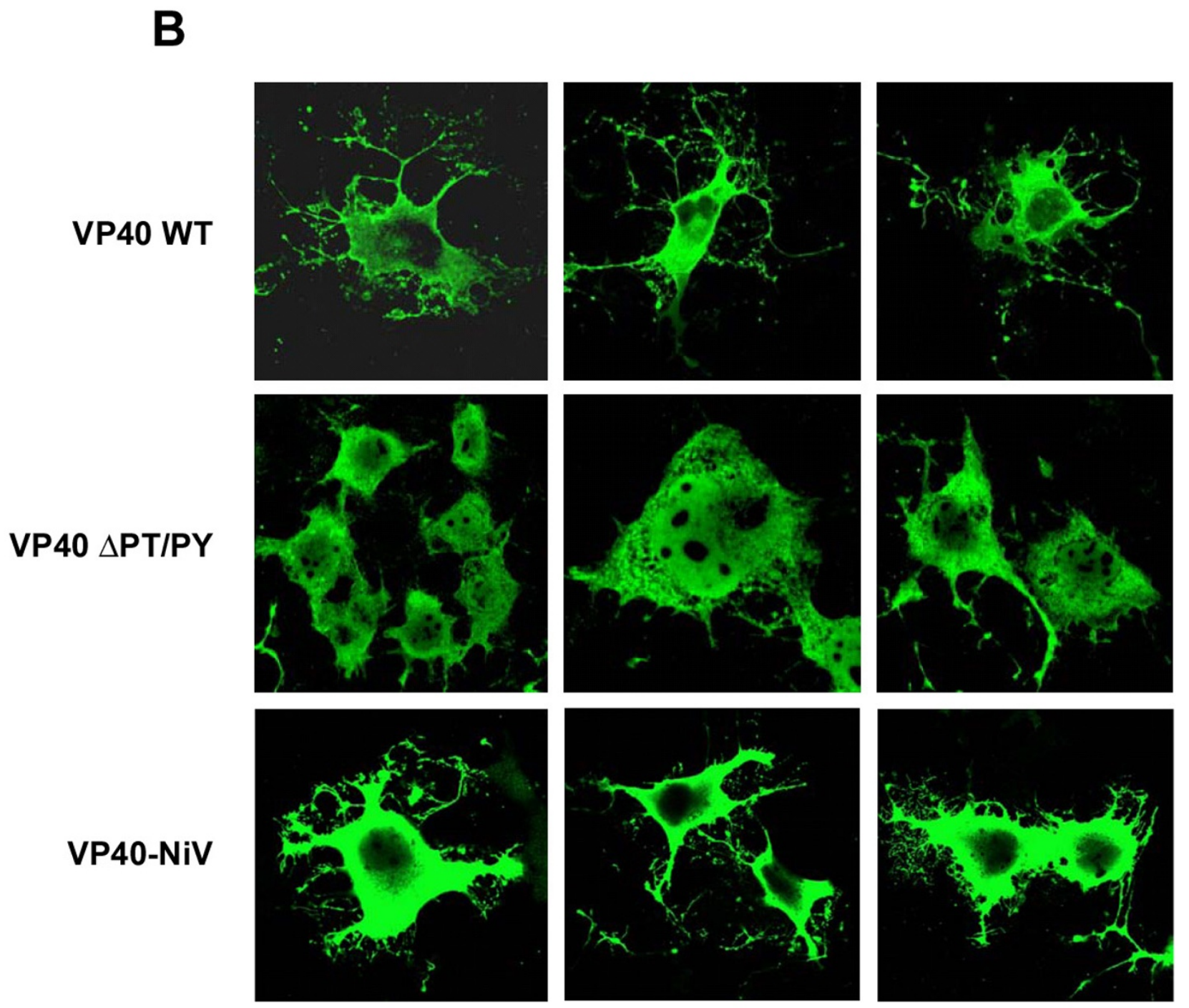

Figure 3

NiV sequence can rescue Ebola VP40-induced cellular morphology. (A) The L-domain and flanking sequence of VP40 (underlined) was replaced with a sequence derived from NiV M (shaded) containing the YPLGVG sequence. (B) COS-I cells were transfected with plasmids encoding VP40 wt, VP40 $\triangle \mathrm{PT} / \mathrm{PY}$, or VP40-NiV. Cells were fixed 20-24 h post-transfection, permeablilized, and incubated with mouse anti-VP40 MAb followed by Alexa Fluor 488 donkey anti-mouse antibody and analyzed by confocal microscopy. The VP40-NiV immunofluorescence experiment was performed separately; all images are representative. 

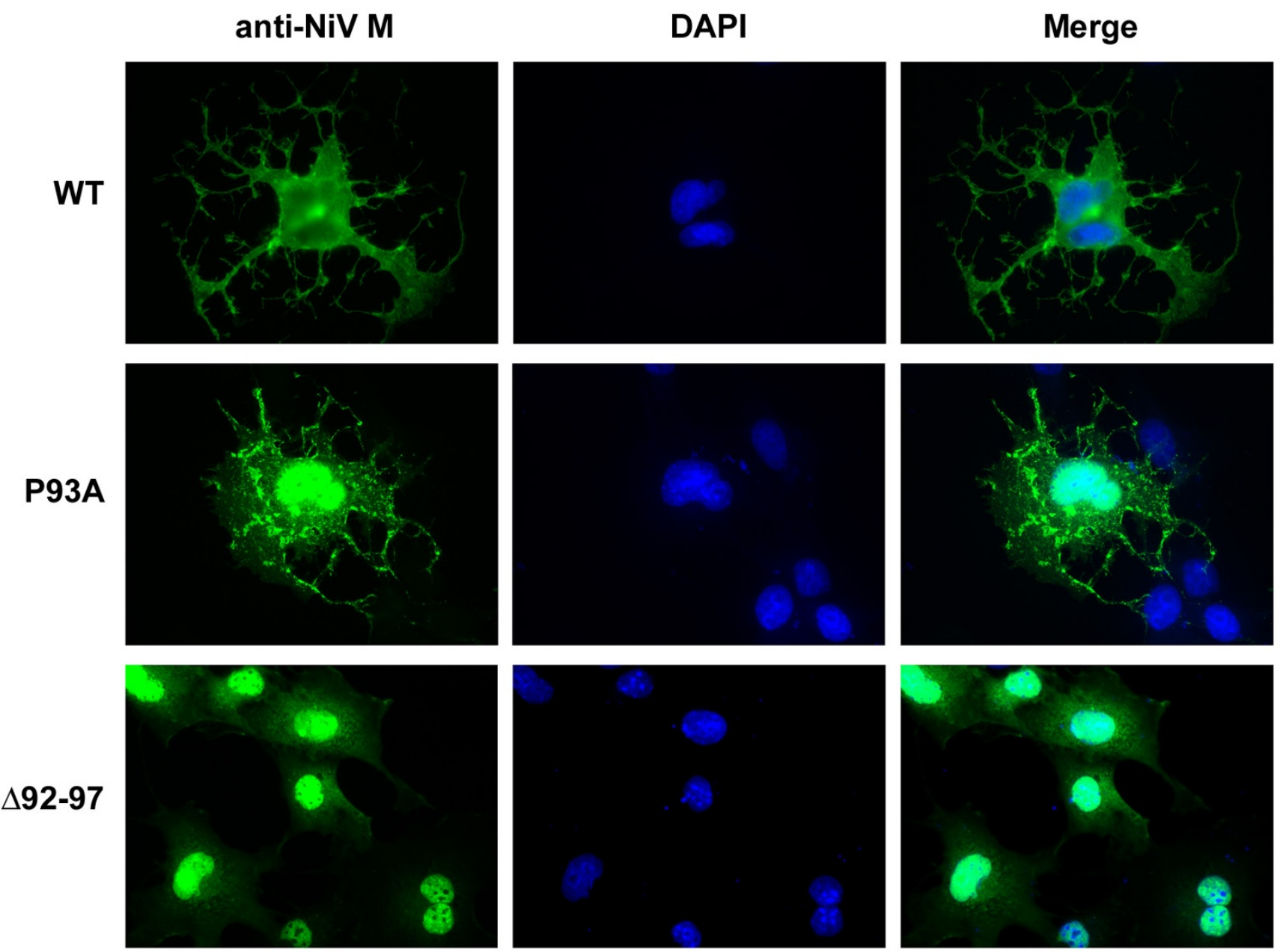

\section{Figure 4}

Cellular morphology of NiV M-expressing cells is dependent on YPLGVG. COS-I cells were transfected with WT, P93A, or $\Delta$ 92-97 NiV M plasmids and treated as described in Fig. 3B and the Methods except MAb F45G5 (anti-NiV M) was used, and cells were visualized by fluorescent microscopy.

\section{Discussion}

Previously, we observed that the $M$ protein of $\mathrm{NiV}$ was capable of budding and forming VLPs when expressed independently in cell culture. In the present study we sought to characterize the $\mathrm{NiV} M$ protein further and explore whether $\mathrm{NiV} M$ possessed a classic L-domain motif that was required for efficient budding. Noting that all well-defined L-domains contain at least one proline residue, we initiated a mutagenesis strategy whereby individual proline residues in $\mathrm{NiV} \mathrm{M}$ were mutated to alanine. We identified 3 sequences (4 proline residues, total) of interest because of their similarity to known L-domain motifs, or close alignment to the SV5 FPIV motif. Using this mutagenesis approach coupled with our NiV VLP budding assay, we identified one particular $M$ mutant (P93A) that was defective in budding. To confirm this observation and further characterize the surrounding amino acids, we targeted the YPLGVG sequence within the $M$ protein and additional alanine mutants were made (Y92A and L94A), as well as deletion mutant (492-97), which were then tested for budding ability. Whereas a low level of P93A release could sometimes be detected, we found the other YPLGVG mutants were completely defective in budding. This sequence motif is conserved in $\mathrm{HeV}$ and a P93A mutation in $\mathrm{HeV} \mathrm{M}$ resulted in diminished budding ability.

To determine whether this sequence has transferable activity, the L-domain motifs and flanking residues of Ebola VP40 were replaced with the YPLGVG motif along with the appropriate $\mathrm{NiV} M$ flanking amino acids. Although budding of the VP40-NiV M recombinant containing the YPLGVG motif was not significantly restored, staining with anti-VP40 mAb and immunofluorescence 

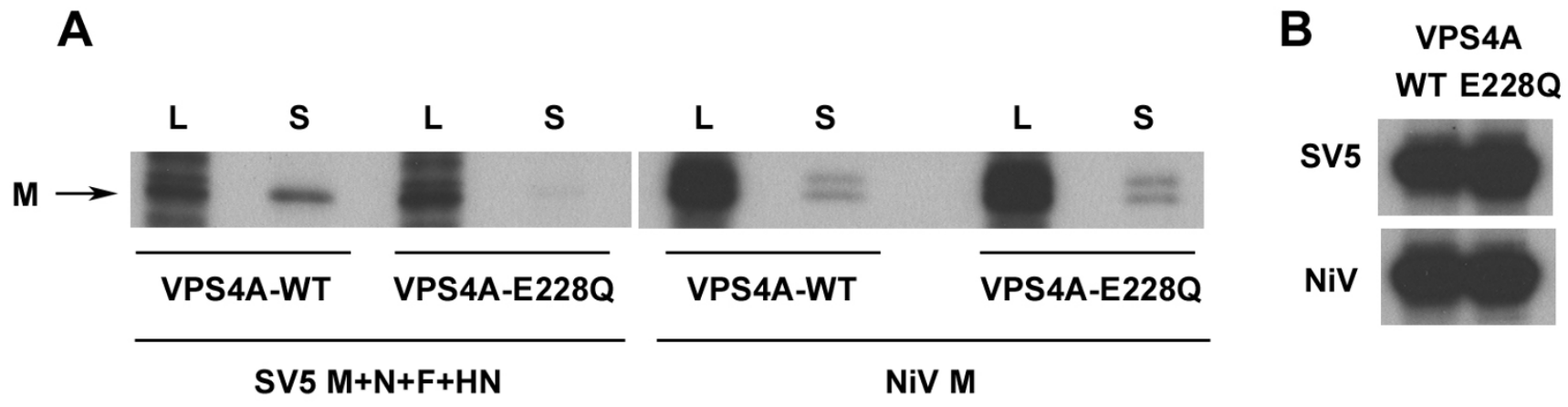

\begin{abstract}
Figure 5
NiV $M$ release is insensitive to VPS4A inhibition. (A) Cells were transfected with expression plasmids for SV5 N, M, $F$ and $\mathrm{HN}$, or NiV M, along with either wild-type or the dominant-negative VPS4A, followed by ${ }^{35}$ S-metabolic labeling. Released protein was pelleted through $10 \%$ sucrose, as described in the Methods, and proteins derived from cell lysates (L) and culture supernatants (S) were immunoprecipitated with either rabbit anti-SV5 polyclonal serum or MAb F45G5 (anti-NiV M) and analyzed by SDS-PAGE followed by autoradiography. (B) Expression of VPS4A was detected in cell lysates from the material analyzed in A by immunoprecipitation with rabbit polyclonal antiserum against GFP, followed by SDS-PAGE and autoradiography.
\end{abstract}

microscopy revealed that cells expressing the VP40-NiV M recombinant containing YPLGVG displayed a morphology consistent with those expressing wild-type VP40 that was characterized by fragmented and branching filamentous structures. Similar morphology was observed for cells expressing wild-type NiV M, whereas mutation or deletion of the YPLGVG motif resulted in either less pronounced or an absence of the filamentous structures accompanied by nuclear localization of the mutant $M$ protein. These data suggest that the YPLGVG sequence motif is important for proper NiV M cellular location and budding and can partially substitute for the native VP40 L-domain sequence. VPS4A and VPS4B are paralogous ATPases that are responsible for disassembly of the Endosomal Sorting Complex Required for Transport (ESCRT) complexes involved in MVB formation, and mutations that destroy their ability to bind or hydrolyze ATP result in the ability to dominantly inhibit cellular VPS4A or VPS4B. These DN mutants inhibited the budding and release of most viruses that use L-domains and are thought to provide a method of global inhibition of class E Vps proteins [30-32,50]. Notably, we found that NiV $M$ budding and release was unchanged in the presence of DN VPS4A, while in parallel, SV5 VLP release was greatly reduced, in agreement with a previous report [38]. Furthermore, NiV M protein release was also unchanged in the presence of DN VPS4B, or in the presence of both DN VPS4A and DN VPS4B, thus eliminating the possibility that NiV M protein release was accomplished by VPS4B or that the wild-type cellular paralogs were rescuing release. We also observed that NiV M release is relatively insensitive to proteasome inhibition and unaffected by AIP1/Alix over-expression (data not shown), further suggesting that NiV M budding is independent of MVB components [31].
We took note of the YPLGVG sequence motif because of its similarity to the known L-domain $\mathrm{YP}(\mathrm{x})_{\mathrm{n}} \mathrm{L}$. This motif was first discovered in the Gag p9 protein of equine infectious anemia virus (EIAV) as YPDL [45] and then later identified in the $\mathrm{p} 6$ domain of human immunodeficiency virus type 1 (HIV-1) Gag protein (YPLTSL) [42]. Initial characterization of this motif in EIAV determined that the $\mathrm{Y}, \mathrm{P}$, and $\mathrm{L}$ residues were critical for virus particle budding; however, the motif was designated YxxL because of the similarity to the YxxL endocytosis motif, and it was hypothesized that the EIAV motif interacted with cellular endocytosis machinery [45]. However, it appears that AIP1/Alix is the primary protein that interacts with this Ldomain, and the EIAV motif is now usually designated as $\mathrm{YP}(\mathrm{x})_{\mathrm{n}} \mathrm{L}$ or YPxL because the proline residue is critical for AIP1/Alix binding and virus particle budding [30-32]. Both HIV-1 and EIAV Gag proteins contain a sequence just downstream of the $\mathrm{YP}(\mathrm{x})_{\mathrm{n}} \mathrm{L}$ motif that is also important for AIP1/Alix binding, and it has been suggested that the two motifs are actually a single motif that can be summarized as $(\mathrm{L})[\mathrm{F} / \mathrm{Y}] \mathrm{Px}_{1-3} \mathrm{LXX}[\mathrm{I} / \mathrm{L}][51]$.

Using the YxxL designation as a guide, Ciancanelli and Basler identified 62-YMYL-65 as a sequence important for NiV M budding [23]. Their study found that alanine mutation of Y62, Y62 and L65, or deletion of the whole sequence resulted in defective $M$ protein budding, with deletion mutants exhibiting nuclear localization. They also established the functional rescue of L-domainmutant VP40 budding by appending the YMYL sequence motif, with flanking elements to the C-terminus of VP40. We attempted to use this observation as a control for our experiments here by directly replacing the native VP40 Ldomain with the identical NiV sequence used in that 
study, as we did with the present YPLGVG motif, rather than appending it to the C-terminus. However, this construct was also unable to restore budding of the L-domainmutant VP40 (data not shown). The reason for the difference is not known; however, L-domains can be contextdependent, which may account for our differing result [31,40-42]. Interestingly, the equivalent sequence in $\mathrm{HeV}$ $\mathrm{M}$ is YMYM, and mutation of the NiV YMYL to the $\mathrm{HeV}$ sequence does not appear to adversely affect NiV M release (data not shown).

Based on their observation of nuclear localization of $\mathrm{NiV}$ M YMYL mutant, Ciancanelli and Basler speculated that NiV M contains competing trafficking signals, and that disruption of targeting to the plasma membrane resulted in the redirection of the protein to the nucleus [23]. Indeed, our observation of nuclear localization of the $\mathrm{NiV}$ $M$ YPLGVG motif deletion mutant used here would be in agreement with this hypothesis, and we speculate that both sequences interact with one or more proteins in a common pathway, resulting in proper targeting of $\mathrm{M}$. However, the mechanistic roles of either of these sequences in henipavirus budding remain to be clarified.

L-domains and their interactions with cellular MVB machinery, most likely represent a subset of protein domains involved in virus budding. An early observation made regarding Gag truncation mutants of HIV-1, which did not express the L-domain-containing p6 protein, was the apparent tethering of budding virions to the cell surface $[31,52]$. This phenotype appears to represent a defect in the final step of virus-cell separation and suggests that mechanisms other than those underlying L-domain function also play an important role in HIV-1 budding. In addition, deletion of the Ebola virus overlapping Ldomains in VP40 results in a modest defect in replication competent virus production and suggests that mechanisms independent of MVB machinery may play a dominant role in Ebola virus budding [53]. The NiV YPLGVG sequence motif may facilitate budding of NiV M via interactions with non-MVB-associated cellular proteins, which enable the associated cellular morphology characterized by extensive filamentous projections that is also seen with VP40, by this alternative mechanism. The observation that NiV M release is insensitive to DN VPS4 proteins and proteasome inhibition lends some support to this interpretation. However, vesicular stomatitis virus (VSV) has been reported to be insensitive to DN VPS4A [44], and EIAV is insensitive to proteasome inhibitors [54-56]. Thus, insensitivity to DN VPS4 proteins and proteasome inhibitors may not be sufficient grounds to rule out Ldomain activity. Further, it also remains a formal possibility that the NiV M protein YPLGVG sequence motif failed to rescue VP40 budding while restoring the filamentous cellular morphology because of the context of the flanking amino acids rather than a lack of intrinsic L-domain function.

Although studies with $\mathrm{SeV}$ have yielded conflicting results, Gosselin-Grenet and co-workers failed to find a reduction in $\mathrm{SeV}$ virion production in the presence of DN VPS4A or during suppression of AIP1/Alix expression. These results suggest that $\mathrm{SeV}$ budding also occurs independent of cellular MVB proteins, and are in agreement with the present observations on NiV M [47]. Chen and Lamb highlighted the reported VPS4 independence of VSV, SeV, and influenza virus and suggested that additional VPS4-independent viruses will serve as tools in uncovering the details of these additional mechanisms of virus budding [50], and our results suggest that $\mathrm{NiV}$ may also be a useful system to explore such alternative mechanisms. Further characterization of the YPLGVG sequence and whether there are any interactions with MVB cellular components in the context of both VLPs and live virus will be needed to definitively establish whether this element possesses classical Ldomain activity or functions through some alternative mechanism.

\section{Conclusion}

Using a recombinant expression system the budding process of the NiV M protein was examined and the amino acid motif YPLGVG within the M protein was found to be essential for $M$ budding. Mutation or deletion of the YPLGVG motif also resulted in nuclear localization of $\mathrm{NiV}$ $M$. The transfer of the YPLGVG motif to an Ebola virus VP40 L-domain mutant did not restore its budding efficiency to wild type levels, but did restore the branched filamentous cell morphology characteristic of VP40 expressing cells. NiV M expression also resulted in the branched filamentous cell morphology, and YPLGVG motif NiV M mutant did not. Unlike classic L-domain containing proteins, we found no evidence of a role for MVB proteins in henipavirus budding. The data here suggest that whatever the specific role of the YPLGVG sequence has in NiV budding it appears distinct from the similar $\mathrm{YP}(\mathrm{x})_{\mathrm{n}} \mathrm{L}$ sequence motif represented by EIAV. Further investigation of henipavirus assembly and budding may reveal a new mechanism of viral assembly and release that could be applicable to other enveloped viruses or have therapeutic implications.

\section{Materials and methods Cell lines}

$293 \mathrm{~T}$ cells were maintained in Dulbecco's modified Eagle's medium (Quality Biologicals, Gaithersburg, MD) supplemented with $10 \%$ cosmic calf serum (Hyclone, Logan, UT), 2 mM L-glutamine, and 100 units/ml penicillin and streptomycin (Quality Biologicals, Gaithersburg, MD) (DMEM-10). COS-1 cells were maintained in Dulbecco's modified Eagle Medium Nutrient Mixture F-12 
(Ham) $1 \times$ (Invitrogen, Carlsbad, CA) supplemented as described above (DMEM/F12-10).

\section{Antibodies}

The following antibodies were used in immunoprecipitations: Monoclonal antibody (MAb) F45G5 (anti-M) [57] was kindly provided by Jody Berry and Hana Weingartl (National Centre for Foreign Animal Disease, Canadian Food Inspection Agency). Rabbit anti-SV5 serum was kindly provided by Robert Lamb (Northwestern University). Polyclonal sera from a rabbit immunized with gamma-irradiated NiV and a MAb directed against VP40 were also used. Rabbit polyclonal antisera against the green fluorescent protein (GFP) was purchased (Invitrogen, Carlsbad, CA).

\section{Plasmids}

The creation of pCAGGS-NiV $M$ has been described previously [22]. The HeV M ORF was PCR amplified from pCP436 (HeV M gene in pTD1) using the primers 5'-GTTTAAACCACCATGGATTTTAGTGTG (HEVMS) and 5'GTTTAAACTCACCCCTTTAGGATCTTC (HEVMAS). PCR was done using Accupol DNA polymerase (PGS Scientifics Corp., Gaithersburg, MD) with the following settings: $94^{\circ} \mathrm{C}$ for $5 \mathrm{~min}$, then 25 cycles of $94^{\circ} \mathrm{C}$ for $1 \mathrm{~min}, 55^{\circ} \mathrm{C}$ for $2 \mathrm{~min}$, then $72^{\circ} \mathrm{C}$ for $3 \mathrm{~min}$. The resulting PCR product was ligated into pCRII-Blunt-TOPO (Invitrogen, Carlsbad, CA), and then sub-cloned as a PmeI fragment into the pCAGGS/MCS SmaI site. Amino acid changes were introduced into NiV M and Ebola VP40 using standard PCR techniques or PCR site-directed mutagenesis using the QuickChange II Site-Directed Mutagenesis Kit (Stratagene, La Jolla, CA). pCAGGS-SV5 M, pCAGGS-SV5NP, pCAGGS-SV5-F, and pCAGGS-SV5-HN were kindly provided by Robert Lamb. Wesley Sundquist (University of Utah) kindly provided pEGFP-VPS4A-WT, pEGFPVPS4A-E228Q， pDsRed-VPS4B-WT， pDsRed-VPS4BE235Q.

\section{Henipavirus matrix budding assay}

$\mathrm{NiV}$ and $\mathrm{HeV} \mathrm{M}$ VLP release was evaluated as previously described [22], with minor modifications. Briefly, 293T cells in $6-\mathrm{cm}$ wells were transfected with $1 \mu \mathrm{g}$ of each expression plasmid (unless otherwise stated) in duplicate using FuGene 6 transfection reagent (Roche, Indianapolis, IN) according to the manufacturer's instructions. At $24 \mathrm{~h}$ post transfection the culture medium was replaced with methionine-cysteine-free minimal essential medium (MEM) (Invitrogen, Carlsbad, CA) containing 2.5\% dialyzed fetal calf serum (Invitrogen, Carlsbad, CA) and 100 $\mu \mathrm{Ci} / \mathrm{ml}{ }^{35} \mathrm{~S}$-cys/met Redivue Promix (Amersham Pharmacia Biotech, Piscataway, NJ). At 20-24 h p.t. the cell culture medium was removed, clarified, and then centrifuged through a cushion of $10 \%$ sucrose (w/vol) (unless stated otherwise) in NTE (100 mM NaCl; $10 \mathrm{mM}$ Tris-HCl, $\mathrm{pH}$
7.5; $1 \mathrm{mM}$ EDTA) at $200,000 \times \mathrm{g}$ for $2 \mathrm{~h}$ at $4{ }^{\circ} \mathrm{C}$. Cells were removed by scraping and lysed in $200 \mu \mathrm{l}$ lysis buffer (100 $\mathrm{mM}$ Tris-HCl, $\mathrm{pH} 8.0 ; 100 \mathrm{mM} \mathrm{NaCl} ; 1.0 \%$ Triton-X 100) containing Complete, Mini protease inhibitors at a $1 \times$ concentration (Roche, Indianapolis, IN). Pelleted VLPs were resuspended in $200 \mu \mathrm{l}$ lysis buffer, and proteins derived from lysates and supernatants were incubated with the appropriate antibody overnight at $4{ }^{\circ} \mathrm{C}$, followed by addition of Protein G-Sepharose (Amersham Biosciences, GE Healthcare, Piscataway, NJ). Proteins were analyzed by SDS-PAGE and autoradiography.

\section{Ebola VP40 budding assay}

The expression plasmids for Ebola VP40 and glycoprotein GP have been generated as described previously [35,49]. A plasmid encoding the VP40-NiV protein chimera was produced by introducing the putative L-domain of $\mathrm{NiV}$ in place of the VP40 L-domain by PCR and inserted into vector pCAGGS using EcoRI and XhoI restriction endonucleases. All introduced mutations were confirmed by automated DNA sequencing. Human 293T cells in sixwell plates were transfected with $2 \mu \mathrm{g}$ plasmid DNA of Ebola GP plus $2 \mu$ g plasmid DNA of VP40WT or VP40-NiV chimera by using the Lipofectamine reagent (Invitrogen, Carlsbad, CA) and the protocol of the supplier. At 20-24 $\mathrm{h}$ post-transfection, proteins were metabolically labeled with $150 \mu \mathrm{Ci}$ of ${ }^{35} \mathrm{~S}$ Met-Cys (Perkin-Elmer, Wellesley, MA) for $5 \mathrm{~h}$. Culture media was centrifuged at 2,500 rpm for $10 \mathrm{~min}$ to remove cellular debris, layered onto a $20 \%$ sucrose cushion in STE buffer (0.01 M Tris- $\mathrm{HCl}$ [pH 7.5], $0.01 \mathrm{M} \mathrm{NaCl}, 0.001 \mathrm{M}$ EDTA [pH 8.0]), and centrifuged at $36,000 \mathrm{rpm}$ for $2 \mathrm{~h}$ at $4^{\circ} \mathrm{C}$. The resulting pellet containing VLPs was suspended in $100 \mu \mathrm{l}$ of STE buffer followed by $300 \mu \mathrm{l}$ of RIPA buffer (50 mM Tris [pH 8.0], $150 \mathrm{mM}$ $\mathrm{NaCl}, 1.0 \% \mathrm{NP}-40,0.5 \%$ deoxycholate, $0.1 \%$ SDS) overnight at $4{ }^{\circ} \mathrm{C}$. The VLPs were immunoprecipitated with the anti-VP40 monoclonal antibody at $4{ }^{\circ} \mathrm{C}$ overnight. The immune complexes were then precipitated with $50 \mu \mathrm{l}$ of a $20 \%$ protein A agarose bead suspension and analyzed by SDS-PAGE. Protein bands were visualized by autoradiography and quantified by phosphorimager analysis.

\section{Indirect immunofluorescence}

COS-1 cells were transfected with plasmids encoding VP40WT, VP40 $\mathrm{PT} / \mathrm{PY}$ or VP40-NiV proteins using Lipofectamine and the protocol of supplier (Invitrogen, Carlsbad, CA), or with plasmids encoding WT NiV $M$, P93A, or $492-97$ using FuGene 6 transfection reagent (Roche, Indianapolis, IN). The cells were fixed with $4.0 \%$ paraformaldehyde in $1 \times$ PBS (fresh-made) at room temperature for $10 \mathrm{~min}$ at $20-24 \mathrm{~h}$ post-transfection, washed three times with $1 \times$ PBS, permeabilized with $0.2 \%$ Triton $\mathrm{X}-100$ in $1 \times$ PBS on ice for $10 \mathrm{~min}$, and washed three times with $1 \times$ PBS. The cells were incubated with either mouse anti-VP40 MAb (1:100), or F45G5 (anti-NiV M) 
$(3: 100)$ in $3 \% \mathrm{BSA} / \mathrm{PBS}$ at $37^{\circ} \mathrm{C}$ in the dark for $30 \mathrm{~min}$ and washed three times, and then incubated with Alexa Fluor 488 donkey anti-mouse antibody (1:500) (Molecular Probes, Invitrogen, Carlsbad, CA) in 3\% BSA/PBS at $37^{\circ} \mathrm{C}$ in the dark for $30 \mathrm{~min}$. The cells were washed three times with $1 \times$ PBS and one time with water, and then mounted with Prolong antifade solution (Molecular Probes, Invitrogen, Carlsbad, CA) and analyzed by confocal immunofluorescent microscopy (VP40) or immunofluorescent microscopy ( $\mathrm{NiV} \mathrm{M})$.

\section{Protein Sequence Alignment}

ClustalW protein alignment was performed using the ClustalW program of the European Bioinformatics Institute http://www.ebi.ac.uk/clustalw and the Jalview [58] multiple alignment editor was used to view the ClustalW alignment. Matrix gene sequences were derived from the following GenBank accession numbers: Nipah virus (NP 112025.1); Tupaia paramyxovirus (NP 054694.1); measles virus (NP_056921.1); Sendai virus (NP 056876.1); Newcastle disease virus (NP 071468.1); simian virus 5 (YP 138514.1). The Hendra virus matrix sequence was derived directly from pCP436.

\section{Competing interests}

The authors declare that they have no competing interests.

\section{Authors' contributions}

JRP conceived and contributed to the development of the $\mathrm{NiV} \mathrm{M}$ budding assay, identified potential late domainlike elements in the $M$ protein, designed and constructed all the $\mathrm{M}$ mutation-containing expression constructs and carried out the recombinant expression and analysis assays, interpreted data, and wrote the first draft of the manuscript. ZH and SEM designed and carried out the Ebola virus VP40 budding assays and interpreted the data. LY assisted in the design and execution of the immunofluorescence microscopy experiments. RNH provided supervision, financial support and edited and corrected the manuscript. LFW edited and corrected the manuscript. $\mathrm{CCB}$ conceived and contributed to the development of the $\mathrm{NiV} \mathrm{M}$ budding assay and mutagenesis approach, provided overall supervision and financial support and wrote and prepared the final versions of the manuscript.

\section{Acknowledgements}

The views expressed in the manuscript are solely those of the authors, and they do not represent official views or opinions of the Department of Defense or The Uniformed Services University of the Health Science. J.R. Patch performed this work as partial fulfillment of the requirements of the Ph.D. program in Emerging Infectious Diseases of the Uniformed Services University of the Health Sciences. We thank Michael Flora and the Biomedical Instrumentation Center staff, as well as Yan-Ru Feng (Uniformed Services University) for assistance. This work was supported by NIH grant Al0547I 5 to C.C.B.

\section{References}

I. Eaton BT, Broder CC, Middleton D, Wang LF: Hendra and Nipah viruses: different and dangerous. Nat Rev Microbiol 2006, 4:23-35

2. Eaton BT, Mackenzie JS, Wang LF: Henipaviruses. In Fields Virology 5th edition. Edited by: Knipe DM, Howley PM, Griffin DE, Lamb RA, Martin MA, Roizman B, Straus SE. Philadelphia, PA: Lippincott Williams \& Wilkins; 2007:I587-I600.

3. Field H, Young P, Yob JM, Mills J, Hall L, Mackenzie J: The natural history of Hendra and Nipah viruses. Microbes Infect 200I, 3:307-3 I4.

4. Anonymous: Hendra Virus, Human, Equine - Australia (07): (Queensland). Pro-MED: International Society for Infectious Diseases 2008.

5. Bishop KA, Broder CC: Hendra and Nipah: Lethal Zoonotic Paramyxoviruses. In Emerging Infections Edited by: Scheld WM, Hammer SM, Hughes JM. Washington, D.C.: American Society for Microbiology; 2008.

6. Chua KB: Nipah virus outbreak in Malaysia. J Clin Virol 2003, 26:265-275

7. Chua KB, Bellini WJ, Rota PA, Harcourt BH, Tamin A, Lam SK, Ksiazek TG, Rollin PE, Zaki SR, Shieh W, et al.: Nipah virus: a recently emergent deadly paramyxovirus. Science 2000 , 288: |432-1435.

8. Hsu VP, Hossain MJ, Parashar UD, Ali MM, Ksiazek TG, Kuzmin I, Niezgoda M, Rupprecht C, Bresee J, Breiman RF: Nipah virus encephalitis reemergence, Bangladesh. Emerg Infect Dis 2004, I 0:2082-2087.

9. Harit AK, Ichhpujani RL, Gupta S, Gill KS, Lal S, Ganguly NK, Agarwal SP: Nipah/Hendra virus outbreak in Siliguri, West Bengal, India in 200 I. Indian J Med Res 2006, I 23:553-560.

10. Anonymous: Nipah virus, fatal - Bangladesh (03). Pro-med: International Society for Infectious Diseases 2008.

II. Anonymous: Nipah virus outbreak(s) in Bangladesh, JanuaryApril 2004. Wkly Epidemiol Rec 2004, 79:168-I7I.

12. Anonymous: Emerging Infections update: November 2004 to January 2005. Communicable Disease Report Weekly (CDR Weekly) 2005, I5:

13. Anonymous: Nipah encephalitis outbreak over wide area of western Bangladesh, 2004. Health and Science Bulletin (ICDDR,B) 2004, 2:7-11.

14. Anonymous: Nipah virus, fatal - India (West Bengal) (02). Promed: International Society for Infectious Diseases 2007.

15. Harcourt BH, Lowe L, Tamin A, Liu X, Bankamp B, Bowden N, Rollin PE, Comer JA, Ksiazek TG, Hossain MJ, et al:: Genetic characterization of Nipah virus, Bangladesh, 2004. Emerg Infect Dis 2005, I I:1594-1597.

16. Chadha MS, Comer JA, Lowe L, Rota PA, Rollin PE, Bellini WJ, Ksiazek TG, Mishra A: Nipah virus-associated encephalitis outbreak, Siliguri, India. Emerg Infect Dis 2006, I 2:235-240.

17. Gurley ES, Montgomery JM, Hossain MJ, Bell M, Azad AK, Islam MR, Molla MA, Carroll DS, Ksiazek TG, Rota PA, et al.: Person-to-person transmission of Nipah virus in a Bangladeshi community. Emerg Infect Dis 2007, 13:1031-1037.

18. Chua KB, Lek Koh C, Hooi PS, Wee KF, Khong JH, Chua BH, Chan YP, Lim ME, Lam SK: Isolation of Nipah virus from Malaysian Island flying-foxes. Microbes Infect 2002, 4: |45-I5I.

19. Reynes JM, Counor D, Ong S, Faure C, Seng V, Molia S, Walston J, Georges-Courbot MC, Deubel V, Sarthou JL: Nipah virus in Lyle's flying foxes, Cambodia. Emerg Infect Dis 2005, I I: I 042-1047.

20. Luby SP, Rahman M, Hossain MJ, Blum LS, Husain MM, Gurley E, Khan $\mathrm{R}$, Ahmed BN, Rahman S, Nahar N, et al.: Foodborne transmission of Nipah virus, Bangladesh. Emerg Infect Dis 2006, I 2: I 888- I 894

21. Lamb RA, Kolakofsky D: Paramyxoviridae: The viruses and their replication. In Fields Virology 4th edition. Edited by: Knipe DM, Howley PM, Griffin DE, Lamb RA, Martin MA, Roizman B, Straus SE. Philadelphia, PA: Lippincott Williams \& Wilkins; 200 I:I305-I340.

22. Patch JR, Crameri G, Wang LF, Eaton BT, Broder CC: Quantitative analysis of Nipah virus proteins released as virus-like particles reveals central role for the matrix protein. Virol J 2007, 4:I.

23. Ciancanelli MJ, Basler CF: Mutation of YMYL in the Nipah virus matrix protein abrogates budding and alters subcellular localization. J Virol 2006, 80: | 2070-|2078.

24. Sugahara F, Uchiyama T, Watanabe H, Shimazu $Y$, Kuwayama M, Fuji Y, Kiyotani K, Adachi A, Kohno N, Yoshida T, Sakaguchi T: Para- 
myxovirus Sendai virus-like particle formation by expression of multiple viral proteins and acceleration of its release by $\mathrm{C}$ protein. Virology 2004, 325: I-10.

25. Takimoto T, Murti KG, Bousse T, Scroggs RA, Portner A: Role of matrix and fusion proteins in budding of Sendai virus. J Virol 200I, 75: II384-II39I.

26. Coronel EC, Murti KG, Takimoto T, Portner A: Human parainfluenza virus type I matrix and nucleoprotein genes transiently expressed in mammalian cells induce the release of virus-like particles containing nucleocapsid-like structures. J Virol 1999 73:7035-7038.

27. Pantua HD, McGinnes LW, Peeples ME, Morrison TG: Requirements for the Assembly and Release of Newcastle Disease Virus-like particles. J Virol 2006, 80: I I062-I I073.

28. Chatziandreou N, Stock N, Young D, Andrejeva J, Hagmaier $K$ McGeoch DJ, Randall RE: Relationships and host range of human, canine, simian and porcine isolates of simian virus 5 (parainfluenza virus 5). J Gen Virol 2004, 85:3007-30I6.

29. Schmitt AP, Leser GP, Waning DL, Lamb RA: Requirements for budding of paramyxovirus simian virus 5 virus-like particles. J Virol 2002, 76:3952-3964.

30. Bieniasz PD: Late budding domains and host proteins in enveloped virus release. Virology 2006, 344:55-63.

31. Demirov DG, Freed EO: Retrovirus budding. Virus Res 2004, 106:87-102.

32. Morita E, Sundquist WI: Retrovirus budding. Annu Rev Cell Dev Biol 2004, 20:395-425.

33. Perez M, Craven RC, de la Torre JC: The small RING finger protein $\mathbf{Z}$ drives arenavirus budding: implications for antiviral strategies. Proc Natl Acad Sci USA 2003, I00: 12978- 12983.

34. Harty RN, Brown ME, Wang G, Huibregtse J, Hayes FP: A PPxY motif within the VP40 protein of Ebola virus interacts physically and functionally with a ubiquitin ligase: implications for filovirus budding. Proc Natl Acad Sci USA 2000, 97: I387| I I 3876.

35. Licata JM, Simpson-Holley M, Wright NT, Han Z, Paragas J, Harty RN: Overlapping motifs (PTAP and PPEY) within the Ebola virus VP40 protein function independently as late budding domains: involvement of host proteins TSGI0I and VPS-4. J Virol 2003, 77:1812-1819.

36. Harty RN, Brown ME, McGettigan JP, Wang G, Jayakar HR, Huibregtse JM, Whitt MA, Schnell MJ: Rhabdoviruses and the cellular ubiquitin-proteasome system: a budding interaction. I Viro 200I, 75: 10623-10629.

37. Harty RN, Paragas J, Sudol M, Palese P: A proline-rich motif within the matrix protein of vesicular stomatitis virus and rabies virus interacts with WW domains of cellular proteins: implications for viral budding. J Virol 1999, 73:2921-2929.

38. Schmitt AP, Leser GP, Morita E, Sundquist WI, Lamb RA: Evidence for a new viral late-domain core sequence, FPIV, necessary for budding of a paramyxovirus. J Virol 2005, 79:2988-2997.

39. Irie T, Shimazu Y, Yoshida T, Sakaguchi T: The YLDL Sequence within Sendai Virus M Protein Is Critical for Budding of Virus-Like Particles and Interacts with Alix/AIPI Independently of C Protein. J Virol 2007, 8 I:2263-2273.

40. Irie T, Harty RN: L-domain flanking sequences are important for host interactions and efficient budding of vesicular stomatitis virus recombinants. J Virol 2005, 79:12617-12622.

41. Martin-Serrano J, Perez-Caballero D, Bieniasz PD: ContextDependent Effects of $L$ Domains and Ubiquitination on Viral Budding. J Virol 2004, 78:5554-5563.

42. Strack B, Calistri A, Craig S, Popova E, Gottlinger HG: AIP I/ALIX is a binding partner for HIV-I p6 and EIAV p9 functioning in virus budding. Cell 2003, II 4:689-699.

43. Accola MA, Strack B, Gottlinger HG: Efficient particle production by minimal Gag constructs which retain the carboxy-terminal domain of human immunodeficiency virus type I capsidp2 and a late assembly domain. IVirol 2000, 74:5395-5402.

44. Irie T, Licata JM, McGettigan JP, Schnell MJ, Harty RN: Budding of PPxY-containing rhabdoviruses is not dependent on host proteins TGSIOI and VPS4A. J Virol 2004, 78:2657-2665.

45. Puffer BA, Parent LJ, Wills JW, Montelaro RC: Equine infectious anemia virus utilizes a YXXL motif within the late assembly domain of the Gag p9 protein. J Virol 1997, 7 I:654 I-6546.

46. Sakaguchi T, Kato A, Sugahara F, Shimazu $Y$, Inoue M, Kiyotani $K$, Nagai $Y$, Yoshida T: AIPI/Alix is a binding partner of Senda virus C protein and facilitates virus budding. I Virol 2005, 79:8933-894I.

47. Gosselin-Grenet AS, Marq JB, Abrami L, Garcin D, Roux L: Sendai virus budding in the course of an infection does not require Alix and VPS4A host factors. Virology 2007, 365:101-II2.

48. Johnson RF, McCarthy SE, Godlewski PJ, Harty RN: Ebola virus VP35-VP40 interaction is sufficient for packaging 3E-5E minigenome RNA into virus-like particles. J Virol 2006, 80:5|35-5|44.

49. Licata JM, Johnson RF, Han Z, Harty RN: Contribution of ebola virus glycoprotein, nucleoprotein, and VP24 to budding of VP40 virus-like particles. J Virol 2004, 78:7344-735।.

50. Chen BJ, Lamb RA: Mechanisms for enveloped virus budding: can some viruses do without an ESCRT? Virology 2008, 372:22I-232.

51. Munshi UM, Kim J, Nagashima K, Hurley JH, Freed EO: An Alix fragment potently inhibits HIV-I budding: Characterization of binding to retroviral YPXL late domains. I Biol Chem 2006, 282:3847-3855

52. Gottlinger HG, Dorfman T, Sodroski JG, Haseltine WA: Effect of mutations affecting the $\mathbf{p} 6$ gag protein on human immunodeficiency virus particle release. Proc Natl Acad Sci USA I991, 88:3195-3199.

53. Neumann G, Ebihara H, Takada A, Noda T, Kobasa D, Jasenosky LD, Watanabe S, Kim JH, Feldmann H, Kawaoka Y: Ebola virus VP40 late domains are not essential for viral replication in cell culture. J Virol 2005, 79: 10300-10307.

54. Khor R, McElroy LJ, Whittaker GR: The ubiquitin-vacuolar protein sorting system is selectively required during entry of influenza virus into host cells. Traffic 2003, 4:857-868.

55. Ott DE, Coren LV, Sowder RC 2nd, Adams J, Nagashima K, Schubert $U$ : Equine infectious anemia virus and the ubiquitin-proteasome system. J Virol 2002, 76:3038-3044.

56. Patnaik A, Chau V, Li F, Montelaro RC, Wills JW: Budding of equine infectious anemia virus is insensitive to proteasome inhibitors. J Virol 2002, 76:264I-2647.

57. Berhane Y, Berry JD, Ranadheera C, Marszal P, Nicolas B, Yuan X, Czub M, Weingartl H: Production and characterization of monoclonal antibodies against binary ethylenimine inactivated Nipah virus. I Virol Methods 2006, 132:59-68.

58. Clamp M, Cuff J, Searle SM, Barton GJ: The Jalview Java Alignment Editor. Bioinformatics 2004, 20:426-427.
Publish with Bio Med Central and every
scientist can read your work free of charge

"BioMed Central will be the most significant development for disseminating the results of biomedical research in our lifetime. "

Sir Paul Nurse, Cancer Research UK

Your research papers will be:

- available free of charge to the entire biomedical community

- peer reviewed and published immediately upon acceptance

- cited in PubMed and archived on PubMed Central

- yours - you keep the copyright
BioMedcentral 